Editorial

\title{
Meeting Our Sustainability Challenges
}

Our species stands at a fork in the road.

One branch is paved with runaway climate change, rising seas, and the humanitarian crises likely to follow in their wake; the reduced soil fertility and loss of genetic diversity of crops associated with industrialized agriculture; life-threatening levels of air and water pollution, especially in the cities of rapidly industrializing, less developed countries; swirling mini-continents of plastic debris choking the world's oceans and the gullets of marine life; and a host of other unmet sustainability challenges that pose an existential threat to the well-being of human individuals, their communities, and their environments in developed and less developed countries alike. That branch of the road seems likely to lead us to a dead end, strewn with the bones of a failed civilization.

The other branch is bright with the light of solar, wind, and other noncarbon-based energy sources; ecologically sensitive agricultural systems that nevertheless provide enough food and fiber for all; new business models that prioritize and incentivize greener and cleaner production; the proliferation of resource recovery and reuse practices and technologies in supply chains for common manufactured goods; and an emerging awareness of and interest in pursuing paths to a human future that does not merely perpetuate the unsustainable mistakes of the past. That branch of the road points the way to a world of sustainable human societies, which will qualify as such by having demonstrated a pervasive, ongoing capacity for facilitating, enhancing, and sustaining indefinitely in that facilitated or enhanced state the well-being of human individuals, their communities, and their environments [1].

Like the readership that we hope to attract, we at the Journal of Sustainability Research (JSR) choose to follow the second route, with a world of sustainable human societies as our goal. Toward that end, we seek to make the JSR a forum for the publication of scholarship likely to contribute to the realization of that vision. As the founding Editors-inChief of the $J S R$, we propose the following principles as essential to achieving that goal.

First, the $J S R$ should be as substantively inclusive as possible. As Editors-in-Chief, we wish to see the journal explore every angle of the multidimensional interface at which the most serious sustainability challenges emerge and must be met if the human enterprise is not merely to persist, but to thrive indefinitely on this planet. We also recognize, however, that we must approach those sustainability challenges holistically if they are to be met at all. Albert Einstein famously stated that no problem can be solved from the same level of consciousness that created it. The unsustainable path on which we now 
find our civilization is largely the result of our collective failure to recognize that the global ecosystem of which humanity is a part is merely a system of systems in which every system is interacting with every other system, either directly or indirectly [1]. As a corrective, we at the JSR are interested especially in providing a forum for scholarship that uses systems thinking to transcend the reductionist perspectives on sustainability implied by the boundaries of academic disciplines. Even so, disciplinary specialists still have a vital role to play in our efforts to meet sustainability challenges holistically. Therefore, we also welcome submissions based on research undertaken from discipline-based perspectives as long as that research is accessible to a multidisciplinary readership and is otherwise relevant to the aims and scope of the JSR.

Second, the content and tone of the JSR should be both progressive and hopeful. One of the pitfalls of being keenly aware of the myriad sustainability challenges that confront our civilization is that our awareness can degenerate into pessimism and paralysis. Although it is true that the sustainability challenges before us are both pervasive and daunting, human history suggests that our species is resourceful enough to meet those challenges, and is able to choose to do so sooner rather than later. More importantly, there is no Planet B to which we can flee if human societies remain unsustainable on this planet, which means that pessimism and paralysis are self-indulgent luxuries that we cannot afford at this time. As Editors-in-Chief of the $J S R$, we therefore seek to publish scholarship that emphasizes not merely the sustainability challenges that confront our civilization, but also the many options for sustainable responses.

Third, the JSR should be universally accessible to an educated, English-speaking audience. This principle could pose a special challenge to researchers trained to interact primarily with a small group of specialists within their own disciplines. We would argue, however, that discipline-based academic isolation is another luxury that neither the academy nor humanity at large can afford. Given the highly multidimensional character of most sustainability challenges, education in the formal sense is necessary but insufficient if contained within the walls of the classroom [2]. We must be willing to extend our vision to address sustainability education in its broadest sense-including training and capacity building, communication, and creating public awareness (in other words, social learning [3])—as an essential prerequisite for the success of sustainability efforts at the scale needed for the emergence of sustainable human societies worldwide. Sustainability scholars and practitioners the world over increasingly have recognized the indispensability of social learning to the success of such efforts. Target 4.7 of UN Sustainable Development Goal 4 [4,5], for example, implies the value of social learning in achieving sustainable development:

"By 2030, ensure that all learners acquire the knowledge and skills needed to promote sustainable development, including, among 
others, through education for sustainable development and sustainable lifestyles, human rights, gender equality, promotion of a culture of peace and nonviolence, global citizenship and appreciation of cultural diversity and of culture's contribution to sustainable development."

In the same spirit, we as Editors-in-Chief of the JSR seek to promote social learning in the service of sustainability by publishing research that is not only forward-thinking, but also accessible enough to be applied by anyone who seeks to do so.

There are probably many different paths that would lead to the emergence of a world of sustainable human societies. For ourselves and those who come after us, bringing that world into being will depend upon the viability of the systems and interactions among those systems on which the sustainability of any human society depends. We at the JSR look forward to providing you with a forum for the publication of research that will contribute to the realization of that vision, and thank you for joining us in that effort.

Founding Editors-in-Chief of JSR

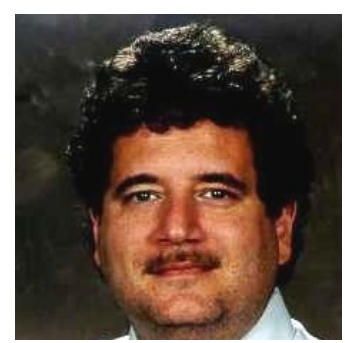

Michael A. Reiter

Professor of Environmental Science Chair, Department of Integrated Environmental Science Bethune-Cookman University, USA Email: reiterm@cookman.edu

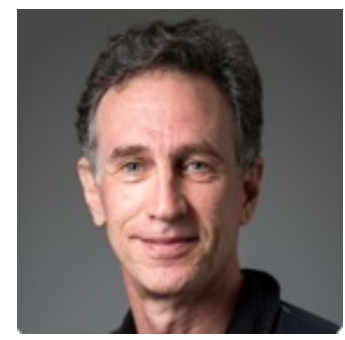

Paul A. Barresi

Professor of Political Science and Environmental Law School of Arts and Sciences Southern New Hampshire University, USA Adjunct Professor of Law, School of Law, Sun Yat-sen University, China Email: p.barresi@snhu.edu 


\section{REFERENCES}

1. Focht W, Barresi PA. The SHES Approach to Sustainability Education. In: Focht W, Reiter MA, Barresi PA, Smardon RC, editors. Education for Sustainable Human and Environmental Systems: From Theory to Practice. Abingdon, UK: Routledge; 2009. p. 62-80.

2. Focht W, Reiter MA, Barresi PA, Smardon RC, editors. Education for Sustainable Human and Environmental Systems: From Theory to Practice. New York, USA: Routledge; 2019. ISBN 9780815399520.

3. Sarabhai KV. ESD for sustainable development goals (SDG). J Educ Sustain Dev. 2015;9(2):121-3.

4. United Nations. Transforming our world: The 2030 agenda for sustainable development. 2015. Available from: https://sustainabledevelopment.un.org/ post2015/transformingourworld/publication. Accessed 2018 May 10.

5. UNESCO (United Nations Educational, Scientific and Cultural Organization). Sustainable development goal 4 and its targets. 2015. Available from: https://en.unesco.org/education2030-sdg4/targets. Accessed 2018 May 10.

How to cite this article:

Reiter MA, Barresi PA. Meeting Our Sustainability Challenges. J Sustain Res. 2019;1:e190001. https://doi.org/10.20900/jsr20190001 